\title{
Group processes and creative components in a problem-solving task with modular robotics
}

\author{
Laura Cassone $^{1}\left[\right.$ Margarida Romero $^{1}\left[\right.$ - Shirin Basiri Esfahani ${ }^{1}$
}

Received: 10 June 2020 / Revised: 27 July 2020 / Accepted: 29 July 2020 /

Published online: 6 August 2020

(C) The Author(s) 2020

\begin{abstract}
Group process assessment is one of the methodological challenges in computer-supported collaborative learning (CSCL). The aim of this study is to analyze the group process dimensions in a problem-solving task with modular robotics in which creative components of fluidity, flexibility and innovation can be observed. The analysis of group process dimensions in relation to the creative components aims to understand the way group processes can support the creativity process in a problem-solving task. For this objective, 24 dyads of in-service teachers in a creative problem-solving task with modular robotics were engaged. The group process dimensions of conversation, social interaction and problem-solving was identified based on a CSCL coding schema developed for the Virtual Math Team environment. The creative components of fluidity, flexibility and innovation are operationalized based on Guilford's Alternate Uses Test's components. The results show the creative component of innovation is related to interactions of support within the dyad. Moreover, the participants dedicating more time to solve the task are engaged not only in more problem-solving interactions with their dyad but also in building more innovative figures, and they also make more figures together. Those results lead us to consider the importance of a positive emotional environment in the context of collaborative creation.
\end{abstract}

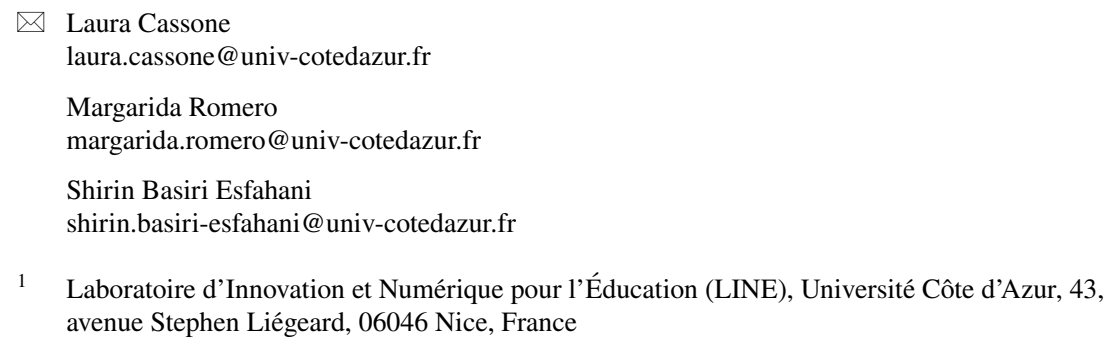


Keywords Alternate uses test · Creativity assessment - Group process · Modular robotics - Virtual math teams

\section{Introduction}

Despite the importance of understanding the group processes in collaborative learning tasks, the assessment of the processes remains a methodological challenge (Jeong and Hmelo-Silver 2010; Ludvigsen et al. 2017). In the context of computersupported collaborative learning (CSCL) activities, group processes are mediated by the technological environments, such as online forums, to support the collaborative activity (Wang et al. 2020). In certain domain-specific tasks, technology can support the group processes through specially designed domains such as the Virtual Math Teams (VMT) environment (Stahl et al. 2006). In CSCL studies, there are different approaches to identify and assess group processes. Within the studies developed from a self-regulated learning (SRL) perspective, Azevedo explored the role of the cognitive, affective, metacognitive, and motivational (CAMM) processes (Cloude et al. 2018) as essential learning components. Winne and Hadwin (1998) proposed a model in which cognitive conditions interact with task conditions (including social context and resources) and control and monitoring processes through SRL processes. Wang et al. (2020) analyze the group process based on Gunawardena et al. (1997) interaction analysis model five phases in the co-construction of new knowledge through different types of cognitive activity: sharing/comparing, dissonance, negotiation/co-construction, testing tentative constructions and statement/application of newly constructed knowledge. Gunawardena's interaction model is specially adapted for online discussions but lacks in the problem-solving dimension which is required in creative problem-solving tasks. In this study, we analyze group processes in a dyadic problem-solving task based on the coding schema proposed by Strijbos (2009) within the VMT environment. Strijbos considered three dimensions of group processes: conversation, social interaction and problem-solving. The research objective of this study is to analyze the relation between these three dimensions of group processes (Strijbos et al. 2006) and creative components of fluidity, flexibility and innovation in a problem-solving task.

Different CSCL studies have distinguished on-task (or task-related) and off-task group processes (Janssen et al. 2012; Tissenbaum et al. 2019). The on-task process is related to the learning activity proposed to the learners. The off-task process is often related to the relational dynamics among the group members. Problem-solving processes are considered on task (Strijbos 2009). Conversation, sometimes also referred as discussion (Janssen et al. 2012), can be on task or off task depending on the topic. For example, conversation is considered on task when the group is discussing strategies to advance the task. Off-task conversation refers to interpersonal verbal exchanges among the group members, for example, critiquing each other's strategies. Social processes, also referred as "affective" processes (Duque Reis et al. 2018), are considered off-task (Janssen et al. 2012) processes.

Within the last decade, the VMT project has offered a computer-supported collaborative learning (CSCL) environment to support mathematics learning (Stahl 
et al. 2004; Sarmiento and Stahl 2007, 2008; Charles and Shumar 2009; Strijbos 2009). At the end of the first year of the VMT project, to investigate chat-based small-group problem-solving, Strijbos (2009) developed a multidimensional coding schema to observe group interactions and distinguished three dimensions of group processes: conversation, social interaction and problem-solving. The conversation dimension refers to the discussion among group members in terms of statements, questions and replies. Strijbos et al. (2004) based the assessment of the social dimension on Renninger and Farra (2003). The social dimension refers to nonverbal communication (e.g., "sustain climate", p. 5) and off-task verbal communication (e.g., "greet", p. 5). The problem-solving dimension refers to "the co-construction of ideas and problem-solving acts circuit flow" (p. 6) (e.g., proposing a strategy or performing a solution step). Strijbos (2009) considered problem-solving one of the dimensions of the group processes and operationalized the assessment of problemsolving based on Pólya and Szegö (1945) and Jonassen and Kwon (2001).

\section{Group creativity in VMT}

Creativity has been evaluated mainly as an individual trait related to divergent thinking (Romero 2019a). However, in teamwork activities, creativity "emerges and exists within a system rather than just at the level of individual process" (Henriksen et al. 2016, p. 27). Researchers have started to explore group creativity in CSCL in recent years (Hämäläinen and Vähäsantanen 2011; Aguilar Camaño and Pifarre Turmo 2019), with an increasing number of studies aiming to identify group processes related to creativity in CSCL settings. Within the VMT environment, Sarmiento and Stahl $(2007,2008)$ observed a synergy between "synchronic interactions (i.e., parallel and simultaneous) and diachronic exchanges (i.e., interaction over long time spans, and mediated by ostensible products)" (2007, p. 43). They reported different episodes of group creativity in VMT activities, such as engaging teammates in "creatively" producing a new mathematical object after establishing shared references and developing "the intersubjective being there-together in a chat", and they characterized group creativity as the "establishment of the conditions and preconditions of its ability to engage in shared meaning making" (p. 41). They also referred to group creativity as the "micro-level co-construction of novel resources for problem-solving to the innovative reuse of ideas and solution strategies across virtual teams" (p. 37). Their analysis described the temporal structure of the interactions and the way the indexation, remembering and bridging of ideas contributes to creatively producing new ideas. Creativity is associated with the generation of novel ideas in the context of VMT activities. In a later study in the VMT environment, Charles and Shumar (2009) observed "creative and imaginative potentials when students attempt to deal with the constraints around learning math" (p. 342). They discussed learners' agency as a creative behavior in which collaborative activities can help "to develop competence to communicate and engage in discursive process, which are paramount to knowledge-building process, e.g., presenting ideas, building connections and refining shared artefacts" (p. 347). The group process described 
by Charles and Shumar (2009) is related to the conversation and social dimensions described in the coding schema of the group processes in VMT developed by Strijbos (2009).

According to Sarmiento and Stahl (2007), creativity is dependent on collaborative interactions that require synchronizing all group members' efforts. In this sense, it is necessary to assess the creative group process as "group-cognitive" accomplishments. Group creativity could be considered a co-construction in which each group member shares the meaning of the task (Stahl et al. 2006). The group members, through developing a shared understanding of the problem, can propose solutions oriented toward a common achievement. Problem and solution proposals arise from the interaction within the group (Stahl et al. 2006). The interactions within the group are part of the group process considered in the multidimensional coding schema of Strijbos et al. (2006). The next section describes these three dimensions of group processes (conversation, social interaction and problem-solving) and introduces the relation of each dimension to creativity based on the existing studies in CSCL and creativity research.

\section{Conversation dimension and creativity}

Conversation is the starting point for building common ground on which to negotiate the meaning of the task. In this context, the group members find room to explain their contrasting perspectives (Fischer et al. 2002). Conversation contributes to make explicit perspectives of different group members that interact during the collaborative task, but conversation does not guarantee per se that each member will reach the same conclusion (Beers et al. 2005). For Strijbos, the conversational dimension is a necessary step to agree on the interpretation of the task. Bakhtin (1986) considered conversation an unpredictable dance between different perspectives. However, while some conversations could contribute to knowledge building and to a creative process through the teammates' interaction, other conversations could be merely procedural (Wegerif et al. 2010). Conversation can support creativity in collaborative learning when the idea exchanges support divergent thinking by generating or modifying the current ideas within the group. Within the different types of interactions, exploratory talk, in which the participant engages in a dialogue toward a shared inquiry, supports a higher verbal creativity than explicit reasoning interactions (Wegerif 2005). In the study of the Lai and Hwang (2014), student's creativity improved when they engage in frequent discussion through mobile learning devices, they discuss the relation between conversation and creativity improvement in relation to the innovating thinking the students can engage when they discuss together.

\section{Social dimension and creativity}

Creativity is supported by a positive climate in the classroom Richardson and Mishra (2017) considered the "atmosphere in which students communicate freely, accept and discuss new ideas, trust each other, and support taking risks" as an ideal climate for the support of creativity; they argued that creativity "can thrive when there 
is a climate of community, care, and cooperation that emphasizes positive student and teacher relationships" (p. 51). In CSCL, a positive team climate has also been observed to be beneficial in the knowledge-building (KB) environment (Hong et al. 2014). Within the Knowledge Forum (KF) environment, Lin et al. (2017) observe an increase in creativity when students are engaged in knowledge-building activities. Moreover, teamwork settings might have beneficial repercussions for creativity when the context promotes ideas and social comparison (Michinov and Primois 2005).

\section{Problem-solving dimension and creativity}

Problem-solving and creativity are considered in most competency frameworks to be distinct competencies (Care et al. 2012). Nevertheless, when authors analyze problem-solving as a process, they often observe creativity within the problemsolving process. Moreover, some authors differentiate creative problem-solving, in which learners engage in diverse processes and solutions, and analytical problemsolving, in which learners engage in a procedural approach to solving a problem (Jarosz et al. 2012). For Piggott (2007), problem-solving in mathematics could be a creative process if the learners are tasked with difficult enough problems that they need to engage in a certain level of risk-taking. The problem-solving dimension in the VMT coding schema of Strijbos et al. (2006) focused on the group process (e.g., "tactic", "clarify", "check", "perform") based on the "problem-based acts" of the collaborative problem-solving through teammates' interactions but did not refer to the specific problem-based engagement in terms of observing the situation, searching for information or resources, or developing representations and solutions. The problem-solving dimension defined by Strijbos et al. (2006) serves to identify the interactions of "problem-solving acts" but must be combined with the observation of the learners' activity within the collaborative task in order to evaluate their collaborative problem-solving competency (OECD 2017).

\section{Creativity assessment}

A better understanding of the relation between the dimensions of group process (Strijbos et al. 2006) and creativity is needed. First, there is a need to operationalize creativity in terms of components. Among the tests used for creativity assessment, Guilford's (1967) Alternate Uses Task (AUT) operationalizes creativity in terms of fluidity, flexibility and innovation. The AUT asks participants to list as many possible uses as possible for familiar objects and assesses fluidity, flexibility and innovation components. The fluidity component corresponds to the total number of alternate uses detected per object. The flexibility component refers to the number of different ideas detected per object. For example, if the participant states that a box can be used to hold clothes and to hold old books, he/she will score two points for fluidity but only one for flexibility. The innovation component is related to the 
uniqueness of each response compared to the total number of given responses to the dataset. The responses considered innovative are those that appear less than $5 \%$ of the time.

Through this study, we aim to evaluate the creativity components of fluidity, flexibility and innovation based on Guilford's AUT in a collaborative problem-solving task using modular robotic cubes. Through the CreaCube task, our research objective is to observe whether relations, and which relations, are incurred between group process and creativity. More specifically, we will observe the relation between Strijbos' VMT conversation, social interaction and problem-solving dimensions and Guilford's fluidity, flexibility and innovation components.

\section{Research objectives}

A better understanding of the relation between the group process dimensions (Strijbos et al. 2006) and creativity is needed. We investigate the relation of the VMT dimensions of group processes and the creative components through the evaluation of eight hypotheses within five research questions:

- RQ1. Does the VMT conversation group process improve the task performance in terms of activity duration (H1) and creativity (H2) in terms of fluidity (H2a), flexibility (H2b) and innovation (H2c)?

- RQ2. Does the VMT social group process improve the task performance in terms of activity duration (H3) and creativity (H4) in terms of fluidity (H4a), flexibility $(\mathrm{H} 4 \mathrm{~b})$ and innovation $(\mathrm{H} 4 \mathrm{c})$ ?

- RQ3. Does the VMT problem-solving group process improve the task performance in terms of activity duration (H5) and creativity (H6) in terms of fluidity (H6a), flexibility (H6b) and innovation (H6c)?

- RQ4. Is a longer task duration related to creativity (H7) in terms of fluidity (H7a), flexibility (H7b) and innovation (H7c)?

- RQ5. Is a greater number of figures made together (collaborative creation) within the dyad related to creativity (H8) in terms of fluidity (H8a), flexibility (H8b) and innovation $(\mathrm{H} 8 \mathrm{c})$ ?

\section{Method}

\section{Research design}

The study has been developed through a mixed-method approach based on the epigenetic analysis of the CreaCube CSCL activity, by comparing the Strijbos' (2009) VMT coding schema VMT coding schema (Strijbos 2009) and the Guilfords' (1967) AUT creative components (Guilford 1967) that we applied to the CreaCube task. In CSCL, the group process has been analyzed mainly through text- and math-based environments (Stahl 2006; Ludvigsen et al. 2017). However, text-based environments might present limits and constraints to learners with language difficulties. In this study, we 
aim to analyze a manipulative robotic task that does not require learners to use language to read the instructions or to perform the task. At the current stage of the literature on group processes in CSCL, robotic tasks have not yet been analyzed. Through this study, we aim to explore the group process in robotic tasks encouraging participants to create by using "visuo-spatial constructive play objects" (VCPOs, Ness and Farenga 2016), including "blocks (for example, standard wood blocks, plastic blocks, and foam blocks), bricks (such as LEGO bricks and Mega Bloks), and planks $(1 \times 3 \times 15 \mathrm{~cm}$ wooden rectangular cuboids)" (p. 202). The operationalization of a task using robotic modular cubes aims to evaluate the way participants solve problems with interactive tangible constructive robotic modules. The CreaCube task uses a set of four cubes, purposely chosen from the Cubelets modular robotic set. The cubes differ in their functionality (and color): the drive cube (white cubes with wheels and motor), the battery cube (dark blue with an on/off switch and a mini USB charger), the distance cube (black cube with a distance sensor) and the inverse cube (red cube without no visible feature). The cubes can be assembled by the magnets on each side of the cubes. When the four cubes are assembled in a certain order, the red cube has the potential to inverse the distance sensor signal and allows the system to activate the wheels motor. By assembling the cubes in several artifacts, the participants discover the features of the cubes and the different behaviors of each artifact.

\section{Participants}

Our sample is composed by in-service teachers in their early career following a continuing education course at Université Côte d'Azur. All of them are at the same stage of experience, in their third year of teaching activity and engaged as in-service teachers in primary education in public schools in the Nice area. The participants are 48 participants, both males and females, aged between 25 and 46 years $(M=31.108$; $\mathrm{SD}=5.770$ ). They have been randomly paired and engaged in participating the activity in dyads. The way dyads were randomly assigned has been better described. The sample is representative of the in-service teachers in France. Primary education in-service teachers show a very similar profile due to the different selection process they follow at the national level. We chose to engage participants in the dyadic modality instead of larger teams to analyze all the actions occurring during the interactions from a microgenetic perspective (Strijbos 2009). Before the start of the activity, the participants were informed that they could interrupt the task anytime and that they could withdraw their consent to participate anytime in the future. The participants provided informed consent and agreed to be video recorded. Only the hands of the participants manipulating the cubes were recorded. This study was approved by the Ethics Committee of Université Côte d'Azur (Comité d'Ethique pour les Recherches non Interventionnelles, CERNI-2019-6). The participants did not receive any compensation.

\section{Procedure}

In order to avoid to influence the participants before they receive the instructions, the cubes and their features (wheels on the white cube, on/off switch and mini USB 
charger on the blue cube, distance sensors in the black cube) were hidden by a cover from the participants' view in order to avoid them to notice prior manipulation. The cubes are set separately as coins of a square instead of aligned, to avoid a Gestalt bias of continuity and closure which would lead the participants to regroup the cubes in a linear way (Todorovic 2008). In the presence of aligned, separated cubes, the participants could have the perception of a broken line and would just regroup them by creating the same shape organized as a continuous line.

The participants were invited to listen to the instructions: "You need to build a vehicle of four pieces that move autonomously from the red point to the black point". The recorded instructions informed the participants that the research team cannot provide any help, but the participants had the possibility to listen again to the instructions. When the instructions were finished and the participants were ready to play, the research team removed the cover that hides the cubes making them finally visible to the participants. The features of the cubes stayed hidden: the battery, wheels, distance sensor and inverter were rotated so that the participants saw just the magnetic sides.

When the participants managed to build a good figure to succeed, the activity is completed. The research team discussed the task with the participants and asked them questions to ensure that they fully understood the role of each cube. We ensured that all possible questions of the participants were answered to enable them to benefit from the knowledge of robotic components and their connectivity developed through the task.

\section{Data analysis}

The video recordings of the dyads were analyzed longitudinally according to our reference apparatus. We coded each occurring relevant action-intended as a "conscious process directed at goals which must be undertaken to fulfil the object" (Augusto and Zhang 2014) —in time slots of $5 \mathrm{~s}$. The analysis of the videos was developed individually for each member $(n=48)$ of the 24 dyads to consider the interindividual differences of teammate contributions in the CSCL tasks.

Through the analysis of the activity duration, calculated in seconds by subtracting the moment of success from the time needed to listen to the instructions, we coded the CreaCube on-task actions, the Guilford's AUT creative components and the Strijbos' VMT coding schema dimensions for each time slot.

We analyzed the CreaCube task resolution procedure by assigning a group process score in relation to the Strijbos' VMT coding schema dimensions (conversation, social interaction and problem-solving) and assigning a creativity score by applying Guilford's AUT fluidity, flexibility and innovation components to the CreaCube task.

In the next section, we describe our reference apparatus. 


\section{Analysis of the CreaCube on-task elements}

After the participants started to manipulate the cubes, they started to discover the affordances together and to show them to each other: that one cube had wheels (affordance cAF01), that the cubes were assembled through magnets (affordance cAF02), that one cube had an on/off switch (affordance cAF03), that the black cube presented two circles (affordance cAF04), and (in some cases) that it is a distance sensor (affordance cAF05). During the task building process, the participants could face different problems that they needed to solve together. A code was used when the participants showed each other that there was a problem: (cP01: imbalance, cP02: rotation, cP03: wrong direction, $\mathrm{cP} 04$ : moving outward, $\mathrm{PP} 05$ : moving toward the participants, cP06: color association, cP07: connection, cP08: not moving due to the wheels, cP09: not moving due to the on/off switch, cP10: moving problem related to the distance sensor, cP11: moving problem related to the inverse cube).

The codes were assigned only when the participants shared the activities together. If one participant ran into a problem on his/her own and did not involve the other (for example, p244 and p281 found the on/off switch but did not mention it to the other participant and waited for the other to discover it on his/her own), no code was assigned because no collaboration occurred.

\section{Analysis of the CreaCube task through the VMT coding schema}

We analyzed the CreaCube task based on the VMT multidimensional coding schema (Strijbos 2009). In this framework, Strijbos' VMT multidimensional coding schema was applied to establish which group process, in terms of conversation, social interaction and problem-solving, was implicated in each creativity component. Although Strijbos' VMT multidimensional coding schema was built to analyze text-based online forum discussions, the analysis of the CreaCube task took into account the coregulation observations from both oral conversation and body language (e.g., agreeing by making a sign with the body). We extracted and personalized from the VMT schema the units relevant to the CreaCube task analysis and assigned each unit a code.

We defined the codes to apply to the conversation (VMTc), social interaction (VMTs) and problem-solving (VMTp) group processes to determine a score (of one point) to each group occurrence within the activity (Fig. 1).

\section{Analysis of the creative components in the CreaCube task}

To assign a creativity score, we applied Guilford's AUT fluidity, flexibility and innovation components to the CreaCube task. The fluidity component corresponded to the total number of figures created. The flexibility component referred to the number of different figures realized. For example, if the participant built two figures, F01 and F02, he/she scored three points for fluidity but only two for flexibility. The innovation component was related to the number of innovative figures compared to the total number of figures created in the dataset. The figures considered innovative were those that appeared less than $5 \%$ of the time. Thus, in terms of Guilford's 


\begin{tabular}{lllll} 
Step 1 & Step 2 & Step 3 & Step 4 & Step 5 \\
\hline C-thread & Conversation & Social & PS-thread & Problem Solving \\
\hline Reply to $\mathrm{U}_{\mathrm{i}}$ & No code & Identity self & Connect to $U_{i}$ & Orientation \\
& State & Identity other & & Strategy \\
& Offer & Interest & Tactic \\
& Request & Risk-taking & Perform \\
& Regulate & Resource & Result \\
Repair typing & Norms & Check \\
Respond, more general & Home & Corroborate/ \\
& than the codes below that & & counter \\
& are tied to problem & & \\
solving: & & Clarify \\
& Follow & School & Reflect \\
Elaborate & Collaborate group & \\
Extend & Collaborate & Summarize \\
& Setup & individual & \\
Agree & Sustain climate & \\
Disagree & Greet & \\
Critique & & \\
Explain & &
\end{tabular}

Fig. 1 Strijbos' VMT multidimensional coding schema

fluidity, flexibility and innovation components, we identified 23 figures, of which F01, F02, F03, F04, F05, F11 and F12 had the potential to be successful figures.

F06, F07 and F09 had limited potential to be considered as successful ones, depending on the micro-level of the building of the artifact (Fig. 2).

F08, F10, F13, F14, F15, F16, F17, F18, F19, F20, F21, F22 and F23 were unsuccessful figures due to the problematic building of the artifact (unbalanced, unconnected, incorrectly rotated) (Fig. 3).

F05, F08, F09, F10, F12, F14, F15, F16, F17, F18, F19, F20, F21, F22, F23 are considered innovative figures (Fig. 4).

\section{Interjudge reliability and interrater reliability}

The dyads were coded independently by two researchers. The interjudge reliability was evaluated through the analysis of the longest dyad recording (dyad bin06, $415 \mathrm{~s}$ ). Each coder autonomously evaluated the video recording. For each action of the video analyzed (67 actions for coder \#1 and 57 for coder \#2), we evaluated the
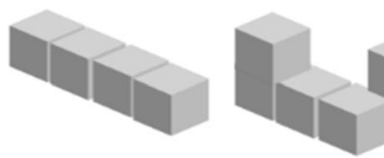

F01

$$
\text { F02 }
$$

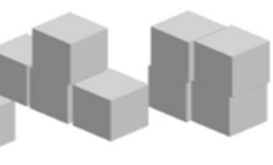

F03

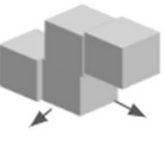

F05

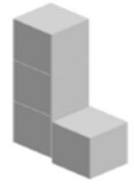

F11

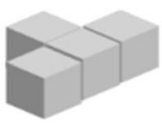

F12

Fig. 2 CreaCube successful figures 


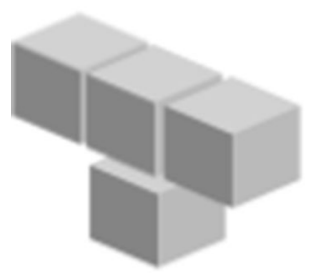

F06

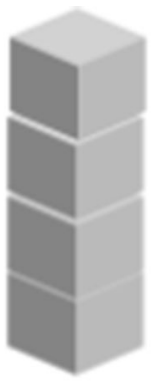

F07

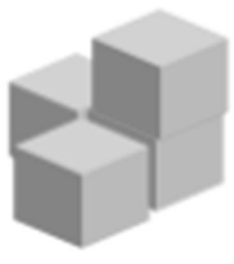

F09

Fig. 3 CreaCube figures with limited potential to be successful
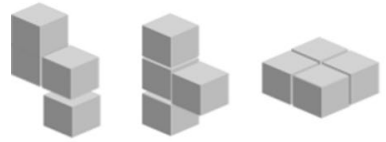

F08

F10

F13

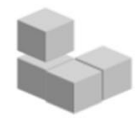

F19

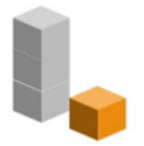

F20

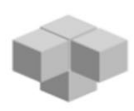

F14

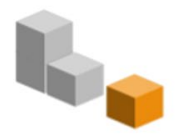

F21

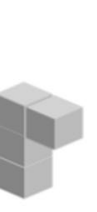

F15

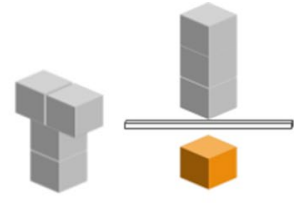

F17

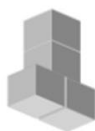

F22

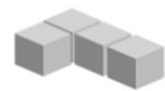

F18

Fig. 4 CreaCube unsuccessful figures

agreement rate based on the total number of observations made at each moment. We considered a difference less than or equal to $1 \mathrm{~s}$ to be the same moment, and if the coders were evaluating the same observation with more than $1 \mathrm{~s}$ of difference, the observations were considered different. For example, if three observations were made of a moment by coder \#1, we verify whether coder \#2 had the same observations. If two of the three observations were the same, the agreement rate for this moment was 0.6. The researchers scored 74 and 91 points, respectively, for an interrater reliability score of 0.813 on 1 point.

\section{Results}

The data analysis developed through the 24 dyads allowed us to answer the 6 hypotheses of this study. The analysis of the relation among the group process and the creative components was developed through Spearman's rank correlation coefficient for nonparametric data. 
The task performance was analyzed through activity duration as a timing factor that could influence the creativity components. The results showed no link between the activity duration and the VMT dimensions of conversation (H1 rejected) and social interaction (H3 rejected). There was a weak link between task duration and VMTp, the problem-solving dimension $(r=0.350, p=0.015)$. Thus, H5 could not be confirmed. However, this weak relation highlighted that the participants who needed more time to solve the task appears to be those who engaged more in problem-solving interactions. The problem-solving dimensions unfolded in 12 units of analysis. When evaluating the relation between the specific problem-solving units and the task duration, we observed a weak link between the duration of the activity and VMTp09 (reflect, real understanding) $(r=0.331, p=0.021)$. The participants who needed more time to develop the task were also those who engaged more in reflection and shared their hypotheses with each other. There was a moderate link between the duration of the activity and the on-task discovery of the affordance of the magnets of the cubes cAF02 $(r=0.414, p=0.003)$ and a weak link between duration and the discovery of the affordance of the sensor cAF05 $(r=0.351$, $p=0.015$ ). The participants took more time to finish the task when the magnetic properties were identified later in the task.

In terms of internal coherence, the CreaCube creative components were significantly correlated with each other. Fluidity was strongly related to flexibility $(r=0.937, p \leq 0.001)$ and innovation $(r=0.684, p=<0.001)$. Additionally, there was a strong link between innovation and flexibility $(r=0.700, p \leq 0.001)$. Furthermore, there was a moderate link between the number of figures made together and fluidity $(r=0.406, p=0.004)$ and flexibility $(r=0.428, p=0.002)$. From this perspective, collaboration seemed to increase the possibility of creating a greater number of different figures.

There were fewer VMTc units $(n=53, M=1.10, \mathrm{SD}=1.53)$ than VMTs units $(n=198, M=4.12, \mathrm{SD}=2.34)$ and VMTp units $(n=129, M=2.68, \mathrm{SD}=2.05)$. The participants who engaged more in conversation showed weak link between fluidity $(r=0.297, p=0.040)$ and innovation $(r=0.285, p=0.050)$. Specifically, the participants who engaged in VMTc12 (agree) $(n=28, M=0.58 \mathrm{SD}=0.73)$ and VMTc13 (disagree) $(n=12, M=0.25 \mathrm{SD}=0.66)$ showed that the participants could benefit both from agreeing and disagreeing. No correlation was found in terms of fluidity (H2a rejected), flexibility (H2b rejected) or innovation (H2c rejected).

The VMT social dimension showed no correlation with Guilford's components ( $\mathrm{H} 4 \mathrm{a}$ and $\mathrm{H} 4 \mathrm{~b}$ were rejected, and $\mathrm{H} 4 \mathrm{c}$ was partly accepted). Within the social dimension, the participants engaged more often in VMTs07 (collaborate) $(n=65$, $M=1.35 \mathrm{SD}=0.95)$, though there was a moderate link between the unit VMTs08 (support) and the innovation component $(r=0.662, p=0.005)$, allowing us to consider $\mathrm{H} 4 \mathrm{c}$, which led us to observe that in a more supportive climate, the participants were more eager to create innovative figures. Furthermore, there was an internal weak link within the social dimension between VMTs07 (collaborate) and VMTs08 (sustain climate, support) $(r=0.345, p=0.016)$, suggesting a possible correlation among the participants being supportive of each other and an increase in their collaboration. 
The VMTp problem-solving dimension was weakly related to task duration. Participants who spent more time completing the task showed a greater number of figures (fluidity) and more different types of figures (flexibility). The results showed a weak link between VMTp problem-solving and fluidity $(r=0.324, p=0.025)$, which did not support H6a, and between problem-solving and flexibility $(r=0.343$, $p=0.017$ ), which did not confirm H6b. The results showed no link with innovation, leading us to reject H6c. More specifically, in the single-unit analysis, the results showed a weak link between VMTp04 (performing problem-solving) and fluidity $(r=0.302, p=0.037)$ and flexibility $(r=0.308, p=0.033)$, suggesting that the participants who were able to engage in problem-solving were more eager to build a greater amount of figures and more different types of figures. Furthermore, there was a very weak link between VMTp02 (elaborate a problem-solving strategy) and VMTp04 (perform problem-solving) ( $r=0.297, p=0.040$ ), suggesting a positive correlation between discussing a strategy together and pursuing an appropriate performance. For example, p280, who acted passively within his dyad, executed zero VMTp units and built zero figures, scoring zero points in both problem-solving and Guilford's creativity components.

The relation between group processes and Guildford's creativity components $(\mathrm{H} 7 \mathrm{a}-\mathrm{c})$ showed a correlation between activity duration and innovation $(r=0.320$, $p=0.026$ ), confirming H7c. The participants who took more time to solve the CreaCube task were more eager to build innovative figures. The lack of a correlation between task duration and fluidity (H7a) and flexibility (H7b) led us to reject these two hypotheses.

There was a link between the number of figures made together within the dyad and Strijbos' VMT conversation unit VMTc12 (agree) $(r=0.329, p=0.023)$, which partly confirmed H8a. The participants who showed more agreement interactions were also more eager to build figures together. The lack of a relation between the number of figures made together and the social interaction and problem-solving dimensions led us to reject $\mathrm{H} 8 \mathrm{~b}$ and $\mathrm{H} 8 \mathrm{c}$.

We summarize the findings in Table 1.

In next sections, we introduce the results in relation to the affordances, the emergent role attribution during collaboration within the dyad, collaboration after problems and positive climate in problem-solving.

\section{Affordances}

Affordances are an important aspect in the CreaCube problem-solving task. We observed a relation between the CreaCube task duration and the moment the participants noticed the affordances of the device, especially the magnets of the cubes (affordance $\mathrm{cAF} 02$ ), showing that they were not just performing a trial/error behavior but engaging in real understanding. We can observe the discovery of the affordances as a relevant factor increasing dyads' collaboration. It appeared that after these "small wins" related to the discovery of the affordances, the participants' engagement, confidence and positivity increased. In the case of dyad bin01, participant p219 manipulated individually until $55 \mathrm{~s}$. After the discovery of the first 


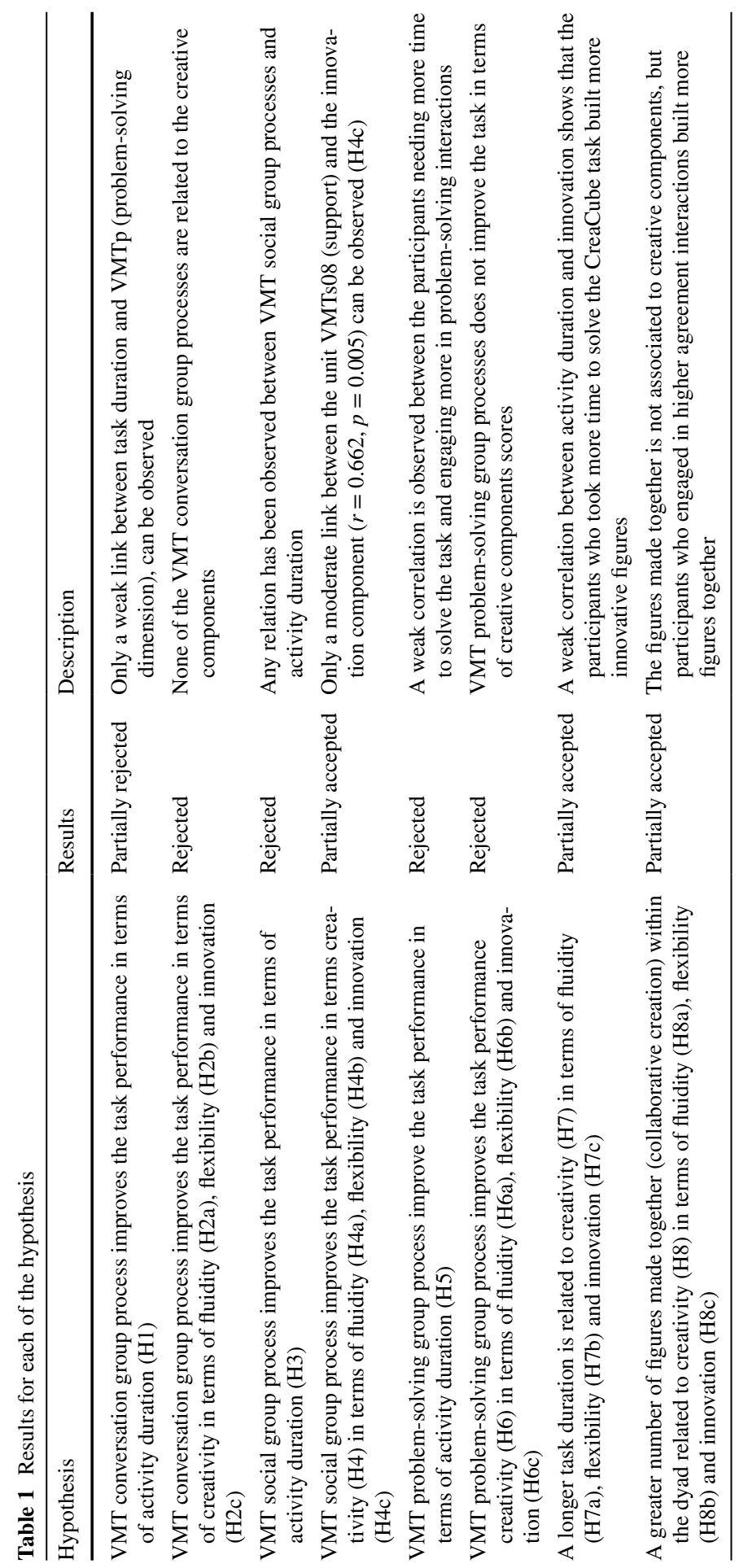


affordance (affordance cAF01), participant p218 also started to manipulate. Discovering the affordances allowed the participants to bond and reinforced their positivity and confidence. Furthermore, we noticed a vicarious learning (Bandura 1965) phenomenon through the observation of the affordances of the material. The participants seemed to learn by simply observing each other. In the case of dyad bin06, p229 determined the affordance of the magnets of the cubes (affordance cAF02) by observing participant $p 228$. This happened very smoothly within a second.

\section{Emergent role attribution during collaboration within the dyad}

In the CreaCube task, specific roles were not assigned to the participants. However, they engaged in specific roles in an emergent division of labor (Engeström et al. 1996). Often, it happened that one participant behaved as the "brain" (reflecting and proposing strategies but more reticent to touch the cubes), and the other behaved as the "hand" (usually the more proactive person, who was not eager to let the other participant access the cubes until he/she realized that he/she was not able to succeed on his/her own). The emergent way of distributing roles among a group has often been observed to be related to knowledge and competency heterogeneity. The literature review of Duque Reis et al. (2018) identified studies in which the performance of heterogeneous groups in online environments was more effective than that of homogeneous groups (Al-Dujaily and Ryu 2007), while in other studies, homogeneous groups achieved better results than those presenting different traits (Manske et al. 2015). In the CreaCube task, we observed in dyad bin02 that participant p221 was domineering and restricting his more submissive teammate's access to the manipulation of the cubes. However, this domination dynamic changed when domineering participant $p 221$ faced a recurrent problem of imbalance. At this moment, participant p220 supported his domineering teammate by providing important cues to overcome the imbalance problem (VMTs08, support). The initially submissive p220 showed at this moment that he was more open to trying other solutions and built a figure that allowed the dyad to succeed in the task. At the end of the activity, p220 showed an increase in confidence, while p221 seemed to be disappointed in not being the one who led the dyad to success. In contrast, in dyad bin10, participant $p 239$ was not willing to touch the cubes, but p240 was finally able to engage him at $110 \mathrm{~s}$ on 170 . Furthermore, in the case of dyad bin11, both participants were unwilling to collaborate and touched the cubes only at $45 \mathrm{~s}$ after asking whether they needed to work together on the resolution process. In this case, a leader figure was missing.

The CSCL environment defines orchestration as a series of efficient, supportive, coordinative actions in performing a learning activity (Fischer and Dillenbourg 2006). This is still a challenge (Dillenbourg et al. 2009), and there is a need for further studies to understand how, and to what degree, the experimenter should orchestrate the activity to facilitate collaboration. 


\section{Collaboration after problems}

Collaboration does not occur spontaneously from the initial moments of the task. Collaboration can be observed after the first exploration process, which is developed by each member of the dyad independently. Synchronicity in collaboration occurs in certain specific moments, which alternates with moments of individual inquiry. In the case of dyad bin18, after encountering a series of six problems, we can observe a decrease on the collaboration leading them to a behavior in which a participant collect all the cubes to work alone on the task.

Other problems encountered during the task, such the rotation problem, leads to disagreement within the dyad. The results showed a link between VMTc13 (disagreeing) and problem P02 (rotation) $(r=0.286, p=0.049)$, suggesting that the participants tended to disagree on how to solve the rotation problem of the artifact.

Problems encountered during the task were also helping the problem-solving process by helping to identify the configuration which required to be excluded. We noticed that the participants tended to reduce the problem space by excluding the nonworking aspects learnt through the analysis of certain problems happening during the task. Once the participants were certain that an aspect of the task was not working, they excluded (inhibited) it, helping the dyad to advance in other solutions if they remembered (by short-term memory) the aspects that should be excluded. This was the case of dyad bin06: 2228 said, "For sure, this is not working", referring to the fifth attempt to solve the task by building F07 and incurring in imbalance problem (P01).

\section{Positive climate in problem-solving}

A positive emotional climate has been observed to support problem-solving (Richardson and Mishra 2017). In this study, we also noticed that a specific group process could be related to a positive emotional environment. For example, there was a link between VMTs09 (greet, cheer) and VMTp04 (perform problem-solving) ( $r=0.288, p=0.047$ ), suggesting that being able to perform an appropriate strategy requires the participants to develop a positive climate within the social interaction dimension (Richardson and Mishra 2017). To do so, further studies on the CreaCube task can consider the group familiarity as a possible factor influencing the social interaction dimension (Janssen et al. 2009).

\section{Discussion}

The group process in CSCL has been studied in relation to mathematical tasks within the VMT project. Group creativity has been explored in terms of shared meaning development in VMT (Sarmiento and Stahl 2007, 2008) but has not been operationalized in terms of the AUT creative components of fluidity, flexibility and innovation. Through this study, we observed some relations between these creative components and the VMT group process that were coded based on 
the conversation, social and problem-solving dimensions developed for the analysis of group process in the VMT environment. An important finding in this study is the time required for efficient creative problem solving. Participants engaging more time to solve the task engaged not only more in problem-solving interactions with their dyad but also in building more innovative and joint figures. Compared to individual learning, collaborative learning might require a greater investment in terms of time and transactional efforts. It is relevant to note that the dyads usually started exploring the cubes individually (for example, p250 started manipulating the blue and red cubes, and p251 started with the white and black cubes), but at some point, there was a need to exchange them. Due to this fact, at the beginning, a single participant could dispose of just two cubes at a time, and it might take longer to determine the special features and thus to succeed in the task (e.g., bin15). The results showed a weak correlation between a longer activity duration and innovation ( $r=0.320, p=0.026$ ), leading us to partially confirm H7c. Moreover, building figures together seemed to increase the possibility of creating a greater number of figures, partially validating hypothesis H8a. However, no relevant correlations were found among the VMT conversation group process and Guilford's AUT components, leading us to reject hypotheses $\mathrm{H} 2 \mathrm{a}-\mathrm{c}$. No prior studies have analyzed this relation.

Within the dyads participating in this study, there was no relation among task performance and the VMT dimensions of conversation (H1), social interaction (H3) and problem-solving (H5). Despite the lack of relation, the analysis of the interactions shows the existence of the exploratory talk within the day, a type of dialogical inquiry within a problem-situation (Wegerif 2005).

Instead, the group process seemed to have an impact on creativity when the participants engaged in the social dimension. Especially when the participants were involved in supporting (VMTs08) each other, they increased in terms of innovation $(\mathrm{H} 4 \mathrm{c})$. This in an important result, which resonates with the importance of a positive team climate for supporting creativity (Richardson and Mishra 2017). Furthermore, in some cases, nonverbal collaboration appeared to be a factor preventing dropout: this was the case for $p 218$, who gave up at $265 \mathrm{~s}$. His partner, participant $p 219$ was supporting (VMTs08) at $280 \mathrm{~s}$, and they succeeded at $310 \mathrm{~s}$. No participants who played the CreaCube task in a dyad dropped out of the task. In contrast, we had dropouts in the individual data collection context with older adults (Romero 2019b). We will pursue our research further to compare individual and dyadic problem-solving in the CreaCube task in further studies to analyze not only the differences in terms of performance but also in terms of creativity.

The link between the VMTp problem-solving dimension and Guilford's AUT creativity components was weak, leading us to reject H6a-c. Though the results showed a weak correlation between the units studying a strategy (VMTp02) and performing problem-solving (VMTp04), we observed this pattern appearing in multiple groups. This was the case for $p 226$, who stated, "We need to do something with balance". p227 put the cubes to the side to balance them. Sometimes the attitude was not positive enough to arrive at a solution. This was the case for $p 276$, who stated, "We need to find the wheels". p277 responded, "But how?" and no problem-solving action followed. This led us to consider deepening our study by assessing, in addition to the 
VMT coding schema (Strijbos et al. 2006) dimensions of conversation, social interaction and problem-solving, a fourth dimension related to the emotional climate.

The sample size of this study is limited due to the level of detail required for developing a microgenetic analysis of the group processes in dyadic problem solving. Despite the sample size limit, the participants are homogeneous in terms of age and profile. The analysis of dyads permits to analyze the group process in a more controlled way than larger groups. However, we consider the analysis of larger groups in further studies to analyze the team size factor in group processes and creative behavior in CSCL tasks.

\section{Conclusion}

Group process assessment in CSCL are important to be studied not only in the context of online forums (Lin et al. 2017; Hong et al. 2014), domain-specific environment (Stahl et al. 2004) but also in tangible constructive tasks such CreaCube. The results of this study are aligned with prior research in CSCL, which highlight the fact that uniting learners in a collective task is not a sufficient condition to ensure collaborative learning (Beers et al. 2005). The learners need to authentically commit their energy to mutual negotiation to elaborate a common understanding of the task (Dillenbourg et al. 2009) and engage in an exploratory talk which can support the inquiry and creative process (Wegerif 2005). Learners must engage in co-construction and share in the meaning of the task via different group processes (Stahl 2006). By exploring the conversation, social interaction and problem-solving dimensions, the CreaCube task allows us to operationalize the relation between the creativity components and the conversation, social interaction and problem-solving aspects of the group processes in dyadic collaboration. The specificities of collaboration through "visuo-spatial constructive play objects" (VCPOs, Ness and Farenga 2016) bring new perspectives to the way we study the CSCL group processes and can be fertile soil for advancing the understanding of the relation between creative components and the group processes not only in textbased environments such the VMT (Stahl et al. 2004; Strijbos 2009) but also in tangible constructive objects. The importance of the educational contributions of this study relies mainly on the role of group processes, specially related to a positive emotional environment, which allows the group to better perform. The educational community should consider and support a positive emotional environment in order to support the collaborative problem-solving activities.

Acknowledgements This study was funded by the ANR Agence Nationale de la Recherche (ANR-18-CE38-0001).

\section{Compliance with ethical standards}

Conflict of interest The authors declare they have no conflict of interest.

Ethical approval All procedures performed in studies involving human participants were in accordance with the Ethical Committee of Université Côte d'Azur (Comité d'Ethique pour les Recherches Non Interventionnelles, CERNI, 2019-6).

Informed consent Informed consent was obtained from all individual participants included in the study. 
Open Access This article is licensed under a Creative Commons Attribution 4.0 International License, which permits use, sharing, adaptation, distribution and reproduction in any medium or format, as long as you give appropriate credit to the original author(s) and the source, provide a link to the Creative Commons licence, and indicate if changes were made. The images or other third party material in this article are included in the article's Creative Commons licence, unless indicated otherwise in a credit line to the material. If material is not included in the article's Creative Commons licence and your intended use is not permitted by statutory regulation or exceeds the permitted use, you will need to obtain permission directly from the copyright holder. To view a copy of this licence, visit http://creativecommons.org/licen ses/by/4.0/.

\section{References}

Aguilar Camaño, D., \& Pifarre Turmo, M. (2019). Promoting social creativity in science education with digital technology to overcome inequalities: A scoping review. Frontiers in Psychology, 10, 1474.

Al-Dujaily, A., \& Ryu, H. (2007). Personality and collaborative learning experience. In Seventh IEEE international conference on advanced learning technologies (ICALT 2007) (pp. 619-621). Niigata: IEEE.

Augusto, J. C., \& Zhang, T. (2014). Workshop proceedings of the 10th international conference on intelligent environments. Amsterdam: IOS Press.

Bakhtin, M. M. (1986). The problem of speech genres. In C. Emerson \& M. Holquist (Eds.), Speech genres and other late essay (pp. 60-102). Austin, TX: University of Texas Press.

Bandura, A. (1965). Vicarious processes: A case of no-trial learning. In L. Berkowitz (Ed.), Advances in experimental social psychology (Vol. 2, pp. 1-55). New York: Academic.

Beers, P. J., Boshuizen, H. P. A., Kirschner, P. A., \& Gijselaers, W. H. (2005). Computer support for knowledge construction in collaborative learning environments. Computers in Human Behavior, 21(4), 623-643.

Care, E., Griffin, P., \& McGaw, B. (2012). Assessment and teaching of 21st century skills. Dordrecht: Springer.

Charles, E. S., \& Shumar, W. (2009). Student and team agency in VMT. In G. Stahl (Ed.), Studying virtual math teams (pp. 207-224). New York: Springer.

Cloude, E., Taub, M., \& Azevedo, R. (2018). Investigating the role of goal orientation: Metacognitive and cognitive strategy use and learning with intelligent tutoring systems. In R. Nkambou, R. Azevedo \& J. Vassileva (Eds.), Proceedings of the 14th international conference on intelligent tutoring systems (pp. 44-53). Amsterdam: Springer.

Dillenbourg, P., Järvelä, S., \& Fischer, F. (2009). The evolution of research on computer-supported collaborative learning. In N. Balacheff, S. Ludvigsen, T. de Jong, A. Lazonder, \& S. Barnes (Eds.), Technology-enhanced learning (pp. 3-19). Dordrecht: Springer.

Duque Reis, R., Isotani, S., Rodriguez, C., Lyra, K., Jaques, P., \& Bittencourt, I. (2018). Affective states in computer-supported collaborative learning: Studying the past to drive the future. Computers and Education, 120, 29-50.

Engeström, Y., Virkkunen, J., Helle, M., Pihlaja, J., \& Poikela, R. (1996). The change laboratory as a tool for transforming work. Lifelong Learning in Europe, 1(2), 10-17.

Fischer, F., Bruhn, J., Gräsel, C., \& Mandl, H. (2002). Fostering collaborative knowledge construction with visualization tools. Learning and Instruction, 12(2), 213-232.

Fischer, F., \& Dillenbourg, P. (2006). Challenges of orchestrating computer-supported collaborative learning. In 87th Annual meeting of the American Educational Research Association (AERA), San Francisco, CA.

Guilford, J. P. (1967). Creativity: Yesterday, today and tomorrow. The Journal of Creative Behavior, 1(1), 3-14.

Gunawardena, C. N., Lowe, C. A., \& Anderson, T. (1997). Analysis of a global online debate and the development of an interaction analysis model for examining social construction of knowledge in computer conferencing. Journal of Educational Computing Research, 17(4), 397-431.

Hämäläinen, R., \& Vähäsantanen, K. (2011). Theoretical and pedagogical perspectives on orchestrating creativity and collaborative learning. Educational Research Review, 6(3), 169-184. 
Henriksen, D., Mishra, P., \& Fisser, P. (2016). Infusing creativity and technology in 21 st century education: A systemic view for change. Educational Technology and Society, 19(3), 27-37.

Hong, H.-Y., Chang, Y.-H., \& Chai, C. (2014). Fostering a collaborative and creative climate in a college class through idea-centered knowledge-building. Instructional Science, 42(3), 389-407.

Janssen, J., Erkens, G., Kirschner, P. A., \& Kanselaar, G. (2009). Influence of group member familiarity on online collaborative learning. Computers in Human Behavior, 25(1), 161-170.

Janssen, J., Erkens, G., Kirschner, P. A., \& Kanselaar, G. (2012). Task-related and social regulation during online collaborative learning. Metacognition and Learning, 7(1), 25-43.

Jarosz, A. F., Colflesh, G. J. H., \& Wiley, J. (2012). Uncorking the muse: Alcohol intoxication facilitates creative problem-solving. Consciousness and Cognition, 21(1), 487-493.

Jeong, H., \& Hmelo-Silver, C. E. (2010). An overview of CSCL methodologies. In Proceedings of the 9th international conference of the learning sciences (Vol. 1, pp. 921-928). Chicago: International Society of the Learning Sciences.

Jonassen, D. H., \& Kwon, H. (2001). Communication patterns in computer mediated versus face-to-face group problem-solving. Educational Technology Research and Development, 49(1), 35.

Lai, C. L., \& Hwang, G. J. (2014). Effects of mobile learning time on students' conception of collaboration, communication, complex problem-solving, meta-cognitive awareness and creativity. International Journal of Mobile Learning and Organisation, 8(3-4), 276-291.

Lin, P. Y., Chang, Y. H., Lin, H. T., \& Hong, H. Y. (2017). Fostering college students' creative capacity through computer-supported knowledge building. Journal of Computers in Education, 4(1), $43-56$

Ludvigsen, S., Cress, U., Law, N., Stahl, G., \& Rosé, C. P. (2017). Future direction for the CSCL field: Methodologies and eight controversies. International Journal of Computer-Supported Collaborative Learning, 12(4), 337-341.

Manske, S., Hecking, T., Chounta, I.-A., Werneburg, S., \& Hoppe, H. U. (2015). Using differences to make a difference: A study on heterogeneity of learning groups. In O. Lindwall, P. Häkkinen, T. Koschman, P. Tchounikine, \& S. Ludvigsen (Eds.), Exploring the material conditions of learning (pp. 182-189). Gothenburg: International Society of the Learning Sciences.

Michinov, N., \& Primois, C. (2005). Improving productivity and creativity in online groups through social comparison process: New evidence for asynchronous electronic brainstorming. Computers in Human Behavior, 21(1), 11-28.

Ness, D., \& Farenga, S. J. (2016). Blocks, bricks, and planks: Relationships between affordance and visuo-spatial constructive play objects. American Journal of Play, 8(2), 201-227.

OECD. (2017). PISA 2015 results: Collaborative problem-solving (Vol. V). Paris: OECD.

Piggott, J. (2007). Cultivating creativity. Prime Number, 22(4), 2.

Pólya, G., \& Szegö, G. (1945). Inequalities for the capacity of a condenser. American Journal of Mathematics, 67(1), 1-32.

Renninger, K., \& Farra, L. (2003). Mentor-participant exchange in the ask Dr. Math service: Design and implementation considerations. In M. Mardis (Ed.), Developing digital libraries for $k-12$ education (pp. 159-173). Syracuse, NY: ERIC Clearinghouse on Information and Technology.

Richardson, C., \& Mishra, P. (2017). Learning environments that support student creativity: Developing the SCALE. Thinking Skills and Creativity, 27, 45-54.

Romero, M. (2019a). From individual creativity to team-based creativity. In Toward super-creativityimproving creativity in humans, machines, and human-machine collaborations. IntechOpen.

Romero, M. (2019b). Analyzing cognitive flexibility in older adults through playing with robotic cubes. In International conference on human-computer interaction (pp. 545-553). Cham: Springer.

Sarmiento, J. W., \& Stahl, G. (2007). Group creativity in virtual math teams: Interactional mechanisms for referencing, remembering and bridging. In Proceedings of the 6th ACM SIGCHI conference on creativity and cognition (pp. 37-44). Washington, DC: ACM.

Sarmiento, J. W., \& Stahl, G. (2008). Group creativity in interaction: Collaborative referencing, remembering, and bridging. International Journal of Human-Computer Interaction, 24(5), 492-504.

Stahl, G. (2006). Group cognition: Computer support for building collaborative knowledge (acting with technology). Cambridge, MA: MIT Press.

Stahl, G., Koschmann, T. D., \& Suthers, D. D. (2006). Computer-supported collaborative learning. An historical perspective. In R. K. Sawyer (Ed.), Cambridge handbook of the learning sciences (pp. 409-426). Cambridge: Cambridge University Press. 
Stahl, G., Shumar, W., \& Weimar, S. (2004). Diversity in virtual math teams. In Proceedings of the 6th international conference on learning sciences (p. 636). Los Angeles: International Society of the Learning Sciences.

Strijbos, J.-W. (2009). A multidimensional coding scheme for VMT. In G. Stahl (Ed.), Studying virtual math teams (pp. 399-419). New York: Springer.

Strijbos, J.-W., Kirschner, P. A., \& Martens, R. L. (2006). What we know about CSCL: And implementing it in higher education. New York: Kluwer Academic Publishers.

Strijbos, J. W., Martens, R. L., \& Jochems, W. M. G. (2004). Designing for interaction: Six steps to designing computer-supported group-based learning. Computers and Education, 42(4), 403-424.

Tissenbaum, C. D., Gnesdilow, D., Martin, N., \& Puntambekar, S. (2019). Emergent roles, collaboration, and conceptual outcomes for two eighth-grade groups in CSCL science classes. In K. Lund, G. P. Niccolai, E. Lavoué, C. H. Gweon \& M. Baker (Eds.), A wide lens: Combining embodied, enactive, extended, and embedded learning in collaborative settings, 13th international conference on computer supported collaborative learning (CSCL) (Vol. 2, pp. 672-675). Lyon: International Society of the Learning Sciences.

Wang, C., Fang, T., \& Gu, Y. (2020) Learning performance and behavioral patterns of online collaborative learning: Impact of cognitive load and affordances of different multimedia. Computers \& Education, 143, 103683.

Wegerif, R. (2005). Reason and creativity in classroom dialogues. Language and Education, 19(3), 223-237.

Wegerif, R., McLaren, B., Chamrada, M., Scheuer, O., Mansour, N., Mikšátko, J., et al. (2010). Exploring creative thinking in graphically mediated synchronous dialogues. Computers and Education, 54, 613-621.

Winne, P., \& Hadwin, A. (1998). Studying as self-regulated engagement in learning. In D. Hacker, J. Dunlosky, \& A. Graesser (Eds.), Metacognition in educational theory and practice (pp. 277-304). Mahwah, NJ: Erlbaum.

Publisher's Note Springer Nature remains neutral with regard to jurisdictional claims in published maps and institutional affiliations.

Laura Cassone is a Ph.D. Student in the ANR \#CreaMaker Project at Laboratoire d'Innovation et Numérique pour l'Éducation (LINE) at Université Côte d'Azur, France.

Margarida Romero is a Full Professor and Research Director of the Laboratoire d'Innovation et Numérique pour l'Éducation (LINE) at Université Côte d'Azur, France.

Shirin Basiri Esfahani is an Intern of the Laboratoire d'Innovation et Numérique pour l'Éducation (LINE) at Université Côte d'Azur, France. 